Stickstoffdioxid- und Feinstaubwerte oft zu hoch

\section{Dicke Luft in der Stadt}

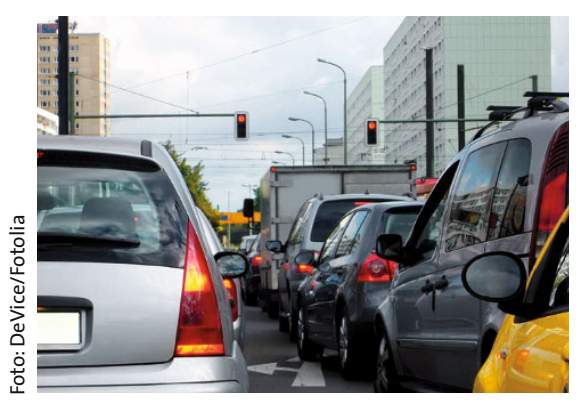

Die zulässigen Feinstaubgrenzwerte werden an stark befahrenen Straßen nach wie vor überschritten.

- Das Umweltbundesamt (UBA) hat die Luftqualität 2009 beurteilt (vorläufiger Bericht unter www.umweltbundesamt.de). Demnach lag die Konzentration an Stickstoffdioxid $\left(\mathrm{NO}_{2}\right)$ bei mehr als der Hälfte der Luftmessstationen über dem seit 1. Januar 2010 geltenden Grenzwert von 40 Mikrogramm/Kubikmeter Luft $\left(\mu \mathrm{g} / \mathrm{m}^{3}\right)$.

„Die Stickstoffdioxidbelastung im Jahr 2009 war ähnlich hoch wie in den beiden vergangenen Jahren. Es ist daher zu befürchten, dass der neue Grenzwert auch im Jahr 2010 an vielen Orten nicht eingehal- ten werden wird“, sagte Jochen Flasbarth, Präsident des UBA.

Grenzwert-Überschreitungen treten vor allem in Städten und Ballungsräumen auf, also dort, wo auch ein Großteil der Bevölkerung lebt. Stickstoffoxide entstammen vornehmlich den Emissionen des Verkehrs sowie den Verbrennungsprozessen in Industrie und Haushalten.

Auch die Feinstaub-Konzentrationen (PM10) überschritten im Jahr 2009 erneut die bereits seit 2005 geltenden Grenzwerte - trotz Maßnahmen in Bund, Ländern und Kommunen. An 23 der insgesamt 408 Messstationen traten an mehr als 35 Tagen PM10-Konzentrationen über $50 \mu \mathrm{g} / \mathrm{m}^{3}$ auf. Insgesamt war die Feinstaubbelastung im Jahr 2009 etwas höher als 2008, dem Jahr, mit der seit 2000 geringsten Luftbelastung durch Feinstaub.

„Die ergriffenen Maßnahmen zur innerstädtischen Luftreinhaltung wie die Einrichtung von Umweltzonen sowie die Verschärfung der Anforderungen an Kaminöfen und andere Kleinfeuerungsanlagen waren richtig und hoch an der Zeit", meinte Jochen Flasbarth, Präsident des UBA. eb
Mit COPD im Flieger

\section{Vorab $\mathrm{O}_{2}$-Druck berechnen!}

- Auf der Website der Deutschen Atemwegsliga können COPD-Patienten kostenlos den Sauerstoffpartialdruck $\left(\mathrm{PaO}_{2}\right)$ im Flugzeug berechnen (www.atemwegsliga.de/ service.php). Die Leitlinien empfehlen die Gabe von Sauerstoff, wenn der $\mathrm{PaO}_{2}$ während des Fluges voraussichtlich unter 50 $\mathrm{mmHg}$ absinkt. Auf langen Strecken werden sogar $55 \mathrm{mmHg}$ empfohlen.

eb

\section{Deutsche rauchen weniger}

\section{„Nur" 1055 Zigaretten pro Jahr und Kopf}

- Die Raucher in Deutschland haben laut dem Statistischen Bundesamt 2009 mehr Geld für ihre Sucht ausgegeben: Insgesamt wurden Tabakwaren im Wert von knapp 22,8 Milliarden Euro versteuert - ein Plus von $1,4 \%$ gegenüber dem Vorjahr.

Allerdings wird in Deutschland immer weniger geraucht. Die erhöhten Steuereinnahmen sind auf Preiserhöhungen zurückzuführen. Da Schmuggelware nicht erfasst werden kann, gilt die Statistik nur als Indiz für den tatsächlichen Konsum.

Im Durchschnitt rauchte jeder Einwohner in Deutschland nach vorläufigen Daten im vergangenen Jahr 1055 Zigaretten. Damit setzte sich der rückläufige Trend der letzten Jahre fort: 2004 hatte der Durchschnitt noch bei 1355 Glimmstängeln pro Einwohner gelegen.

Sehr stark rückläufig waren die versteuerten Absatzmengen von Pfeifentabak $(-57,2 \%)$ sowie von Zigarren und Zigarillos (-24,6\%). Der Absatzeinbruch beim Pfeifentabak sei vor allem auf die geänderte steuerliche Behandlung der sogenannten Pseudo-Pfeifentabake zurückzuführen, die seit Juli 2008 mit dem höheren Steuersatz von Feinschnitt besteuert werden.

Nach der Preiserhöhung für Zigaretten Mitte vergangenen Jahres drehen viele Raucher wieder selbst. Der Absatz von Feinschnitt stieg 2009 um 11,7\% gegenüber dem Vorjahr an.

ÄZ 